\title{
A methodology for the selection of enterprise information system based on the analytic hlerarchy process
}

D.S. LUO

Dept. of Machinery Engineering. China Junior College of Technology, 245, Section 3, Yan Jiow Yuann Rd., Taipei, Taiwan, R.O.C.

K.J. FARN

Computer Center, Industrial Technology Research Institute, Building 11, 195. Section 4, Chung Hsing Rd., Chutung, Hsingchu, Taiwan 31015, R.O.C.

Abstract: In this paper, an evaluation and selection model is proposed. This new model combines the Analytic Hierarchy Process (AHP) with the Information System Management Planning (ISMP). The ISMP is chosen as the hierarchy-constructing method. That is to define the global enterprise infor-

mation system scheme, and its evaluation criteria and weights by the headquarters of enterprise.

The group decision making method of the AHP is also modified in the proposed model in order that each organization (local enterprise) may apply this model easily. So that the goal of combining the evaluation and development for organization (local enterprise) information system can be reached.

It is found that the proposed model can not only match the global enterprise information system scheme but also meet the needs of group decision making under multi-criteria. Hence the new model is expected to be able to provide more reasonable and practical results.

Key words: Analytic hierarchy process, enterprise information system, group decision making, information system management planning, multi-criteria 


\section{Introduction}

The evaluation and selection for an information system (IS) is quite different from the purchase of other goods. The major differences are: the various complex options of an IS. the demands of an IS depending on the total requirement of operations. the explosive growth of informauon technology, and the difficulties in estimating cosi and benefit of total IS. etc. Many inodels which have been proposed for the evaluation and selection of an IS focused on various aspects: for example. the criteria like costbenefit (Ahiruv and Igbaria [2]. Shoval and Lugasi [11]). empirical models (Griese and Kurpicz [4]), and mathematical models (Lehman. et al. [6]. Shoval and Lugasi [10]).

But the most imporiant aspect of an IS is that of management. So. when evaluating and selecting IS, it is important to select an appropriate model based on management characteristics and then evaluate under multiple criteris by group decision-making (Fichefet [3]). A]so, practically, the ealuation and selection of an IS for each organization (local enterprise) depends on its development. environments, and budget. Whatever the result is: it should match the global enterprise information system scheme. The model presented combines the Analyuic Hicrarchy Process (AHP) and the Information System Management Planning (ISMP). It is expected to meet the above needs and provide more reasonable and practical results

\section{Principles of the ABP}

The AHP breaks down the decision problem into separate elements. i.e., a hierarchy structur- ing. then obtains pairwise comparison matrices through the pairwise comparison of all elements. It sets the relative weights (importance) by the eigenvalue method. Finally, it determines the overall priotities of altersatives. In decision-making. it may measure the consistency of each level and the overall hierarchy by means of a consistency ratio (C.R.). The important foundations of the AHP's hierarchy constructing and group decision-making are as follows:

\section{(1) bierarchy construction}

The AHP decomposes a complex problem from high level to low level by a hierarchy. In constructing a hierarchy, it assumes that all entitues of each level are independent of each other. then it decomposes the problem into levels of goal. objective. criteria. and alternative (see Fig.1) ( Saaty [7]).

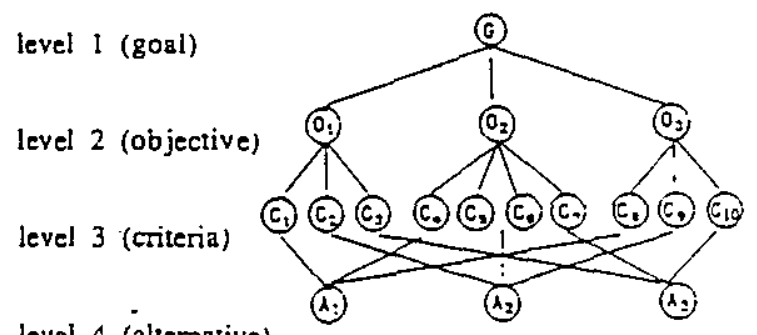

level 4 (alternative)

Fig.1 Hierarchy stoucture of the AHP

\section{(2) group decision making}

in decision-making. individual judgments about the measurement or ratio of objects are always subjective and are easily changed because of the environment. By the way, the decision environ. ment frequently changes and many decisions are hard to be made by individuals. In order to make betrer decisions, group decision making has recendy been employed to conquer the risks in the 
decision process and to mold individual opinions into a group opinion.

In [8], Saaty stated that there are two ways to integrate multiple decision makers' opinions in the process of the AHP. One is to debate the judgments and vote until consensus or compromise is reached. the other is to take the geomet. ric mean of individual judgments to form a combined judgment in a group.

a. debating and voting

When in pairwise comparison, all decision makers have full debate on each priority. Undoubtedly. in social choice process. it is ideal that each decision is made by way of group in. teraction. But the process of debating and voting is liable to be time consuming.

When applying this method, one will probably encounter the following special problems: unequal power and expertise, variable preferences, changes in preferences, and unwillingness to reveal preferences (Saary [8]).

b. the geometric mean as synthesizing function

Let $a_{l j}{ }^{(x)}$ be the element of the Kih decision maker's judgment matrix. the element of the overall group may be get by

$$
\left.a_{u}=\sum_{k=i}^{n} a_{d}^{(k)}\right)^{1 / n} \quad(1 \leq i, j \leq n i .
$$

The primary reason for using the geomeric mean is that it may preserve the reciprocal property after synthesizing. The way io decide how well an individual's set of judgment corresponds with the group's is also determined by the consistency ratio (C.R.).

Saary [9] let $\left(a_{i j}\right)$ be an $n^{*} n$ pairwise comparison marrix formed by taking the geometric mean of the individual judgments, and let $\left(W_{1}, W_{2}, \ldots . .\right.$.
$W_{n}$ ) be the weights derived from this matrix.

Since $A_{w}=\lambda_{\mathrm{mas}} W$, so

$$
\begin{aligned}
& \sum_{j} a_{L j} y_{j}=\lambda=x H_{i} \\
& \sum_{i, j} a_{i j} w_{j} / H_{i}=n i_{\max } .
\end{aligned}
$$

The consistency index (C.I.) is computed by

$$
\text { ( } \pi \lambda_{\operatorname{mex}}-n^{2} / n^{2}=\left(\lambda_{\max }-n\right) / n \text {. }
$$

The consistency ratio (C.R.) is computed as usual by taking the ratio of C.i. to the random index (R.I.). Saaty [9] also suggested tha: if the CR. is less than 0.10. then the group judgment is consistent. We have critique on the above point of view because the consistency (consensus) of the decision group can not simply be derived from individual consistency.

Besides the geometric mean, there are other synthesizing functions used. Aczel and Alsina [1] discussed the synthesizing judgment of the AHP. and compared some synthesizing functions.

From the above, it is known that up to now there is not an effective method to synthesizing group judgments in the A.PP. Either the debateand-vote method. or the synthesizing functions method has its own advantages and disadvantages. It is noticeable for the decision maker ( DM) that the former has many difficulties in practice. while the latrer can only simplify the problem. without diminishing the social intricacy.

\section{Information system management planning(ISMP)}


There is no certain process for constructing hierarchies in applying the AHP. This paper addresses the evaluation and selection of the enterprise IS. so we construct the decision hierarchy from the view of the management of the enterprise IS.

The most important part of developing an is is to define its goal and scheme in order to meet the enterprise objectives. With a top-down flow. the planning and control hierarchy is determined. from strategic level, tactical level, to operational level. With a bottom-up flow, the development of the IS is identified by five stages as follows: star up. growth. control, planning, and strategic planning.

As Fig.2 (IBM [5]) shows, under each objective are the processes which are combined into several process groups. The information flow be. tween the process groups also tells the relationship of processes. The above scheme may define the global is strategic planning.

The accomplished is planning should at least include the following tasks: 1) definition of bụsiness processes, 2) relationship of business processes and organization, 3) analysis of data utilization. 4) data classes. 5) relationship of data and business processes. 6) total IS scheme. 7) design of application system, 8) structure and performance specification of each application system. 9) information boundary of application system. 10) design of data base.

\section{The proposed model}

The proposed model is based on the AHP. combines the ISMP as the hierarchy constructing method in order that it may match the global enterprise IS scheme. The group decision making method of the AHP is also modified. The P. connectivity matrix procedure is chosen as the group decision making method on the level of altemative so that it may provide a more reasonable result in practice.

The proposed model, as shown in Fig.3, includes three methods: ISMP. AHP. and the group decision making method.

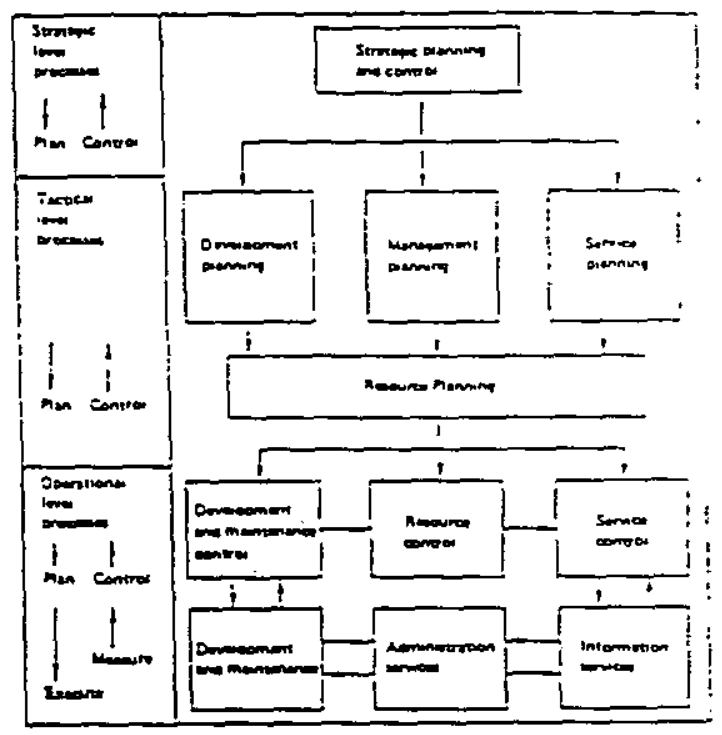

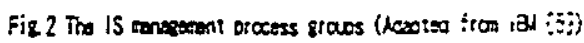

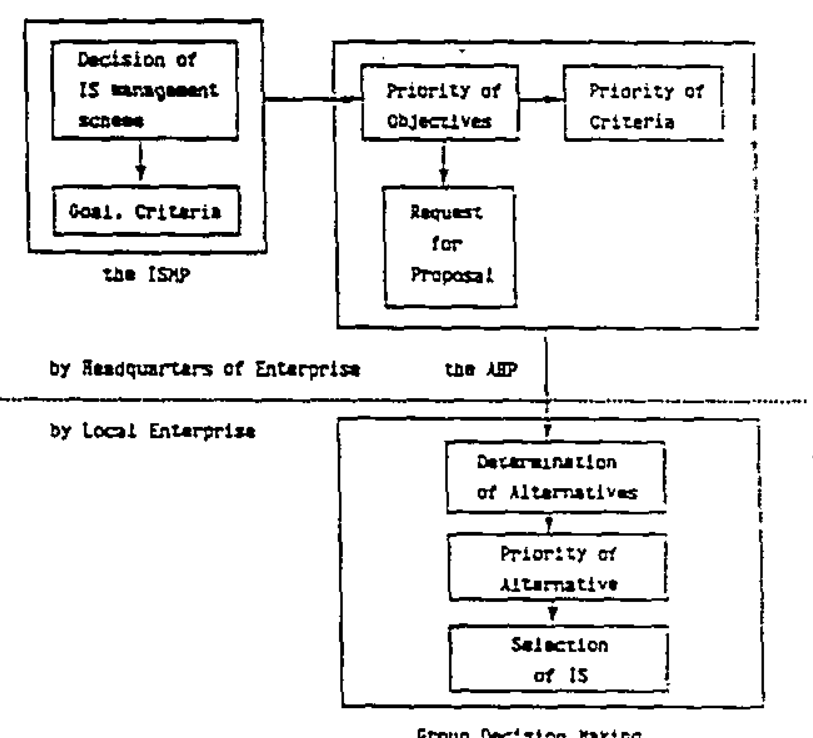

Group desion vaxing for Local Entarpr:se

518.3 The codel combined whe NHP and the T5up for evaliation anc selectzon of encerprise is 


\section{(1) the ISMP}

Each local enterprise has many IS needs in common, so the ISMP should be performed by a group made up of headquarters of enterprise and expers. In this way, it may be economical and provide foundations for latter developments. Then the global is scheme may act as the decision hicrarchy.

In hierarchy constructing, there are various aspects to be discussed. First, when the hierarchy is incomplete, one may get counterintuitive composite weights (Zahedi [13]). The process groups in ISMP may contribute to all levels above them in the hierarchy: that is, if well-planned there will not be any incomplete hicrarchy. Second. the organizational hierarchy is different from a decision one. so the evaluation criteria table of each applitication system's performance and atributes is necessary. Third. the formulation of the decision structure may employ the backward process (is yet. to be developed into an operational method). We suggest that the planners of the ISMP should decide what those important elements are in order to construct the decision hierarchy.

\section{(2) the AHP}

From the global IS scheme, system function and system attributes of the ISMP decision hierarchy, the AHP here may decide the priorities of all subsystems; then define the weights of performance and attributes for evaluation. Also, the request for proposal (RFP) may be defined. Finally. the local enterprise may choose its own alternative from the above result submitted to it, then the overall decision hierarchy may be constructed.

(3) the group decision making
Above the level of altematives. for the sake of consistency and the reciprocal property, the geometric mean is employed to synthesize individual judgments into group judgment. While at the level of alterantive, the P-connectivity matrix procedure is employed as a synthesizing function for the following reasons: firstly, to meet the developments of each local enterprise with the independence principles; and secondly, to meet the least violation principle, reflecting individual judgment into group judgment which is not dominated by anyone.

The P-connectivity matrix procedure is a modification of the Borda count method (Tzeng et al. (121), it finds out the complete outranking order after the pairwise comparison of the alternatives by each individual: then assigns marks of a-1, n-2...., 0 to the first ranked, second ranked, ...... last ranked alternative ( $\mathrm{n}$ is the number of alternatives). All individual preference can be calculated by the sum of outranking order position between pairwise altematives (i, i'). Then the least violation principle may be satisfied, the, group preference may be summarized by all in dividual preferences.

(4) the strategies to solve the possible problems

In the AHP, all the elements (evaluation criteria) of any level should satisfy the trade-off properry. Both the elements of the criteria and altemative level satisfy the above needs. In the present model, we can avoid the above need by taking into consideration the subsystems in the objective level separately and giving each subsystem its own hierarchy.

In addition to the inherent problems in AHP. such as evaluation ratio scale and consistency. other intrinsic problems are as follows:

a. rank reversal 
When we evaluate the alternatives, all alternatives must be evaluated at one time. There will possibly be rank-reversal (different ranking) when we add or delete altematives after the evaluation

b. adjustment of element's weights

The weight of each element should pertain its relative weight to each subsystem. without converting to the overall weight relative to the goal. In this way, the DM may flexibly choose the subsystem to be evaluated (e.g.. choose part of the subsystems).

c. cost factor ratio

Generally, for example. the cost factor ratio of personal computer and peripheral equipments ranges from $30 \%$ to $50 \%$. To meet the requirements of cost/benefit of. IS, the cost factor ratio may be included in the model presented. The range may be decided by the decision group. whether the cost factor included in weighted calculation or not is also determined by the decision group.

\section{Applications}

In this paper, an evaluation example is cited. In this enterprise, the first part of this model ( ISMP) is already completed, and then this model is applied to the evaluation and selection of the enterprise's data base management system ( DBMS).

\section{(1) a brief view of the example}

The enterprise requests an information Co. to plan a long-term development scheme of its national IS. With the ISMP (e.g.. Business System Planning developed by IBM Co.), the business processes/data classes have been analyzed several times and the business processes via similar data utilization are clustered in one group. The total group numbers are 26: that is. 26 manggement subsystems are planned. The global IS scheme has been constructed. Most tasks as the Section 3 proposed are done. It takes half a year to finish the "Global Planning Report" and the "Construct Planning Report".

The above repors suggest that a huge and ef ficient DBMS is quite necessary in order that all business may be included in the DBMS. Here comes the problem of how to evaluate and select a proper DBMS.

\section{(2) the evaluation process}

As the Tabie 1. shows, the primary requirements of the DBMS are determined according to the is scheme.

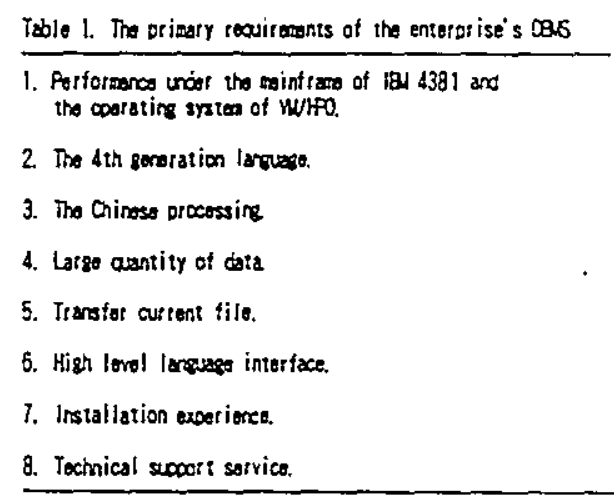

The decision group (composed of five individuals, e.g., $A, B, C, D$, and $E$ ), by referring to the above reports. determines the important criteria ( $I$ criteria) and the reference criteria ( $R$ criteria) for evaluation of the DBMS. Then the evaluation hierarchy of the DBMS may be constructed, as the Fig.4 shows. 


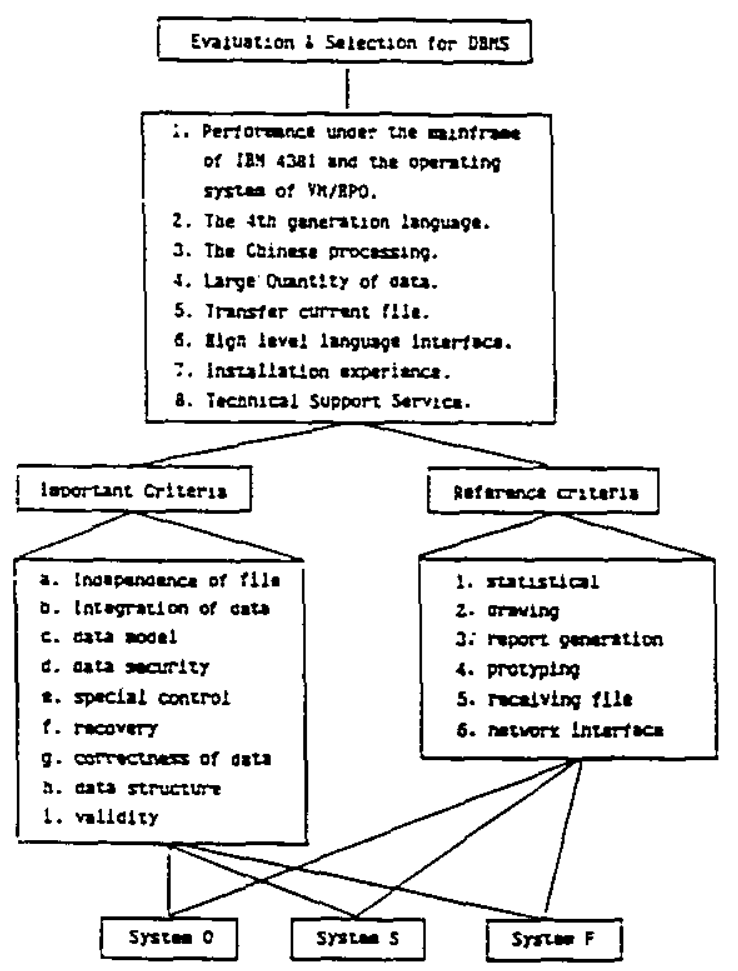

تig.4 Eveluacion hieratchy of the JBus
The decision group determines the weights of each element (except the level of alternatives) by pairwise comparisons. The results of the second level are as follows:

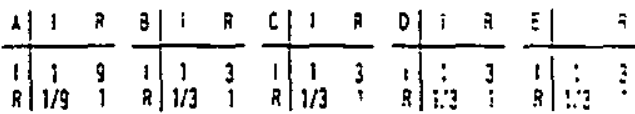

$1=(0.90 .6 .10)$

$r=(0.750 .09)$

$=(0.70 .25)$

$=(0.7 .0 .25)$
$=(0.7)$

the $v_{i}$ means the outranking vector of DM i's pairwise comparison matrix. The synthesized judgments are

\begin{tabular}{|c|c|c|c|c|}
\hline 01 & $i$ & & $R$ & Helọtrs \\
\hline 1 & 1 & $\sqrt[5]{ }$ & $9 \times 3 \times 3 \times 3 \times 3$ & $0.7 \mathrm{~s}$ \\
\hline$R$ & $\sqrt[5]{1 / 9 \times 3}$ & $\overline{\times 3 \times 3}$ & 1 & $0.2:$ \\
\hline
\end{tabular}

$\lambda=2.00 ; c .: .=0.00$

to the overall evaluation. the weight of the I criteria is 0.79 : while the weight of the $R$ criteria is 0.21 .

The nine evaluation criteria under the I criteria. and the six evaluation criteria under the $R$ criteria. may also be pairwisely compared as the above procedure does. Each result is shown in Table 2 and Table 3.

iable 2. The reights at at:terta une ine inta

\begin{tabular}{|c|c|}
\hline Corteria & elgn: \\
\hline 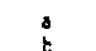 & 0 \\
\hline 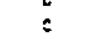 & 0.3 \\
\hline 0 & ti. \\
\hline 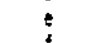 & 0.02 \\
\hline & $\because$ \\
\hline $\begin{array}{l}8 \\
n\end{array}$ & 6.24 \\
\hline I & 0.05 \\
\hline
\end{tabular}


Faple 3. The aights of eriserta unoer the R criteria

\begin{tabular}{|c|c|}
\hline Corter ad & Wight \\
\hline $\begin{array}{l}1 \\
2 \\
3 \\
\vdots \\
\vdots \\
5 \\
5\end{array}$ & $\begin{array}{l}0.25 \\
0.18 \\
0.20 \\
0.04 \\
0.18 \\
0.15\end{array}$ \\
\hline
\end{tabular}

Then all weights of evaluation criteria relative to the overall hierarchy are compured, shown in the Table 4.

iable: ito eergnts of all criteria

\begin{tabular}{|c|c|}
\hline Cinter-a & MeIgnt \\
\hline $\begin{array}{l}a \\
j \\
c \\
\vdots \\
\vdots \\
i \\
8 \\
h \\
i\end{array}$ & $\begin{array}{l}0.103 \\
0.095 \\
0.134 \\
0.079 \\
0.016 \\
0.087 \\
0.158 \\
0.095 \\
0.024\end{array}$ \\
\hline $\begin{array}{l}1 \\
2 \\
3 \\
4 \\
\vdots \\
0 \\
0\end{array}$ & $\begin{array}{l}0.053 \\
0.038 \\
0.042 \\
0.008 \\
0.038 \\
0.032\end{array}$ \\
\hline
\end{tabular}

With the bench-mark or the questionnaire abour all evaluation criterie for each vendor: the decision group makes pairwise comparison of the three aiternative (i.e., O.S. and F) under each evaluation criterion. The complete outranking order may be computed from the complete outranking weight of each alternative by every DM. The evaluation of DM A is shown in the Table 5. In synthesizing judgments about altemative, as the Section 4 mentioned. the P-connectivity matrix procedure is as follows:
Table 5. Evaluation of alternative for od $A$

\begin{tabular}{|c|c|c|c|}
\hline Criteria & Srate 0 & Srsten S & Srsten $\bar{r}$ \\
\hline $\begin{array}{l}a(0.103) \\
v(0.095) \\
c(0.134) \\
d(0.079) \\
o(0.016) \\
t(0.087) \\
z(0.158) \\
h(0.095) \\
i(0.024) \\
1(0.053) \\
2(0.038) \\
3(0.042) \\
4(0.008) \\
=(0.039) \\
5(0.032)\end{array}$ & 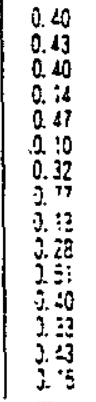 & $\begin{array}{l}0.20 \\
0.14 \\
0.20 \\
0.63 \\
0.47 \\
0.33 \\
0.22 \\
0.17 \\
0.21 \\
0.75 \\
0.13 \\
0.20 \\
0.23 \\
0.12 \\
0.33\end{array}$ & 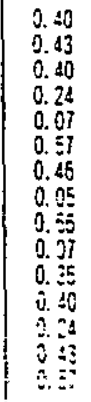 \\
\hline 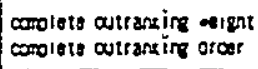 & ग. 3 & $\begin{array}{c}0.28 \\
3\end{array}$ & ง. 涼 \\
\hline
\end{tabular}

the Borda count matrix of the three alternative is

$$
\stackrel{0}{5}=\left[\begin{array}{lllll}
1 & 3 & c & 0 & \vdots \\
2 & 2 & 1 & 1 & 1 \\
0 & 0 & 0 & 0 & 0 \\
1 & 1 & 2 & 2 & 2
\end{array}\right]
$$

In P-connectivity matrix procedure. the Borda count matrix is

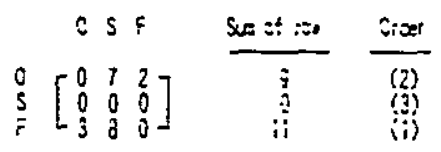

It is bown that the system $F$ is the 1st ranked choice. If the cost factor is taken into consideration, the decision group has to determine each ratio of cost under the above technique. The weights unultiplied by the ratio may also determine the complete outraning weight of each alteruative.

\section{Summary and conclusions}


The evaluation and selection of is possesses the characteristics of multi-criteria and group participation. To meet the reasonable and practical purpose. the group decision making under multiple criteria is applied in this proposed model.

The ISMP is chosern as the hierarchy-constructing method which may define the global enterprise IS scheme. The evaluation criteris and weights are also determined by the headquarters of enterprise.

For the selection of alternatives, the group decision making method of the AHP is modified in order that each organization (local enterprise) may easily apply this model. Since the least violation principle is met, the modified method is reasonable.

The proposed model, combining the AHP and the ISMP, can surely match the global enterprise IS scheme. Once the global enterprise IS scheme is constructed, all organizations may follow the scheme, and then a long term development is expected.

The proposed model derives the evaluation criteria from the global enterprise IS scheme to form a decision hierarchy. All the evaluation criteria will match the global enterprise IS scheme, the adtematives evaluated from the above criteria will aiways do so.

Future research may make efforts in the following three topics. One is the development of other evaluation and selection models which are more practical and effective for enterprise is. Another is a better synthesizing method to eliminate the broad criticism about the group decision making of the AHP. The other is the employment of more empirical studies to refine the present model.
[1] Aczel, J., and Alsina. C., "On synthesis of judgments". Sacio-Econ. Plann. Sci. 20(6) (1986) 333-339.

[2] Abituv, N., and Igbaria. M., "A model to facilitate cost, pricing and budget of computer services" , Information and Masagement 14(1988) 235-241.

[3] Fichefet, J., "Computer selection and multicriteria decision aid". In $G$. Fandel and J. Sproni (Eds.). Multiple Criteria Decision Metbods and Applications 337.346. Springer-Verlag. New York. 1985.

[4] Griese, J.. and Kurpicz. R.. "Investigating the buying process for the introduction of data processing in small and medium-sized firms". Information and Management 8 (1985) 41-51.

[5] International Business Machines Co., A Management System for the Information Business - Volume I: Managemeat Orervier, IBM Co., New York. 1981.

[6] Lehman, J., Wetering. J. V., and Vogel. D., "Mainframe and microcomputer based business graphics: What satisfies user?" , Ioformation and Management 10(1986). 133-140.

[7] Saaty, T. L., The Aas/rtic Hiesarchy Process McGraw-Hill, New York 1980.

[8] Saaty, T. L., Decision Makjng for Leaders, RWS Publications, Pirsburgh, 1988.

[9] Saaty, T. L., "Group decision making and the AHP" , In B. L. Golden. E. A. Wasil. and P. T. Harker (Eds.), The Analytic Hierarchy Process - Applications and Studies 59-67, Springer-Verlag, New York, 1989.

[10]Shoval, P., and Lugasi, U., "Models for computer system evaluation and selection" Information and management 12(3) (1987) 117-129.

[II]Shoval, P., and Lugasi, U.. "Computer sys- 
tems selection: The graphical cost- benefit approach" , Information and Management 15(1988) 163-172.

[12]Tzeng, G. H.. Dang. J. Y., and Lin, S.G.. "Evaluation of strategy for air quality improvements through evaluation" , Transportation Quarterly 4(1989) 9-30.

[13]Zahedi. F., The analytic hierarchy process - A survey of the method and its applications" . Interfaces 16(4) (1986), 96-108. 